\title{
Preparation, characterization, and continuous manufacturing of nonflammable colorless and transparent semi-alicyclic polyimide film modified with phenoxy-phosphazene oligomer flame retardant
}

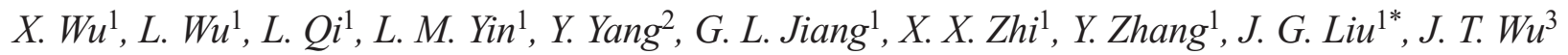 \\ ${ }^{1}$ Beijing Key Laboratory of Materials Utilization of Nonmetallic Minerals and Solid Wastes, National Laboratory of \\ Mineral Materials, School of Materials Science and Technology, China University of Geosciences, 100083 Beijing, China \\ ${ }^{2}$ Composites Center of Commercial Aircraft Corporation of China, Ltd., 201324 Shanghai, China \\ ${ }^{3}$ Key Laboratory of Bioinspired Smart Interfacial Science and Technology of Ministry of Education, School of Chemistry, \\ Beihang University, 100191 Beijing, China
}

Received 16 July 2020; accepted in revised form 10 September 2020

\begin{abstract}
Phenoxy-phosphazene (PPZ) oligomer (Rabitle ${ }^{\circledR}$ FP100) flame retardant (FR) was successfully incorporated into the colorless and transparent semi-alicyclic polyimide (CPI) film matrix derived from 1,2,4,5-cyclohexanetetracarboxylic dianhydride (CHDA) and 4,4'-oxydianiline (ODA) (PI-a, CHDA-ODA). The PPZ FR showed good miscibility with the PI-a matrix with a loading amount of up to $10 \mathrm{wt} \%$ in the composite films. PI-b (CHDA-ODA-FP100-5) film maintained good optical properties with the transmittance of $83.9 \%$ at the wavelength of $400 \mathrm{~nm}$, the yellow index $\left(b^{*}\right)$ of 3.28 , and the haze of $2.14 \%$. PI-b film also showed good flame retardancy with the limiting oxygen indices (LOI) of $41.2 \%$ and the flammability rating of UL94 VTM-0. In addition, PI-b film exhibited the obviously reduced heat release rate (HRR) and total smoke production $(T H R)$ during the cone calorimeter measurement. At last, PI-b showed the glass transition temperature $\left(T_{\mathrm{g}}\right)$ and $5 \%$ weight loss temperature $\left(T_{5 \%}\right)$ of 325.0 and $404.3^{\circ} \mathrm{C}$, respectively, which was slightly lower than those of the pristine PI-a film $\left(T_{\mathrm{g}}=346.8^{\circ} \mathrm{C} ; T_{5 \%}=431.6^{\circ} \mathrm{C}\right)$. Continuous PI-b films with a length of $1000 \mathrm{~m}$ and a width of $1000 \mathrm{~mm}$ were successfully obtained on the demonstration production line by optimizing the processing parameters via the modified solvent cast technology. Similar thermal, optical, and flame retardancy properties and obviously improved tensile properties were observed for the mass production of PI-b film.
\end{abstract}

Keywords: polymer composites, semi-alicyclic polyimide, colorless polyimide film, flame retardancy, phosphazene oligomer

\section{Introduction}

The past decades have witnessed the rapid development of the optoelectronic industry, including flexible electronics, flexible display, wearable devices, flexible solar cells, and other promising applications [1]. Advanced polymeric materials play very important roles in the achievement of such new technologies due to their intrinsic lightweight, high specific strength, flexibility, and diverse structural designability $[2,3]$.
Among various polymeric materials for optoelectronic applications, optical films with high transparency, low yellow indices, low haze, good flame retardancy, and high thermal and dimensional stability have received extensive attention due to the increasing requirements for high reliability, high integration, high pliability, and high signal transmission speed in the fabrication of optoelectronic devices [4]. For example, in the fabrication of flexible active matrix, 
organic light-emitting display devices (F-AMOLEDs), optically clear and high-temperature resistant polymer films have been highly desired as components for flexible substrates, flexible cover windows, flexible touch panels, and other devices due to the processing temperature as high as $300^{\circ} \mathrm{C}$ [5-8]. As mentioned in our previous review article [9], in the 'optical polymers pyramid', colorless and transparent polyimide (PI) films at the top position of the pyramid are good candidates meeting these severe performance requirements.

PI films have been known as a class of high-performance polymer films for more than half a century since their first commercialization in the 1960s in the United States. Standard wholly aromatic PIs are usually characterized by the strong intra- and intermolecular interactions in the rigid-rod imide-fused benzene molecular skeletons. Such structural characteristics, on the one hand, endow the PI films excellent thermal, mechanical, electrical, and dielectric properties; however, on the other hand, deteriorate the optical transmittance and color parameters of the standard PI films at the same time due to the formation of charge-transfer complexes (CTC) between the electron-donating diamine moiety and the electron-withdrawing dianhydride units [10-15]. Up to now, nearly all of the methodologies on the improvements of the optical properties of the standard PI films have been focused on how to reduce the strong interactions between the molecular chains. Several effective methods have been established in developing colorless and transparent PI (CPI) films, including reducing the $\mathrm{CTC}$ formation via incorporation of substituents with high electronegative feature [1618], or with low or non-conjugated structure [19]. Among the developed CPI films, the semi-alicyclic ones based on alicyclic dianhydrides and aromatic diamines usually exhibited the superior combined optical, thermal, and mechanical properties compared with the fluorine-containing or sulfone-containing wholly aromatic counterparts [20-25]. This is mainly due to the good reactivity of the alicyclic dianhydrides and obviously reduced charge-transfer interactions between the diamine and dianhydride moieties. However, semi-alicyclic CPI films, such as those derived from hydrogenated pyromellitic dianhydride (HPMDA) or hydrogenated 3,3',4,4'-biphenyltetracarboxylic acid dianhydride (HBPDA) and aromatic diamines usually suffer from the deteriorated flame retardancy due to the combustible nature for aliphatic or alicyclic units in the polymers. For instance, wholly aromatic PI films, such as the one derived from pyromellitic dianhydride (PMDA) and 4,4'-oxydianiline (ODA), known as Kapton ${ }^{\circledR}$ film (Dupont, USA), showed a hydrogen/carbon $(\mathrm{H} / \mathrm{C})$ ratio of 0.0382 and a limited oxygen index (LOI) of $37.0 \%$. However, when the PMDA was changed to HPMDA, the derived semi-alicyclic CPI films with the $\mathrm{H} / \mathrm{C}$ ratio of 0.0610 showed a reduced LOI of $27.4 \%$ (current work). Another example is the system of Upilex ${ }^{\circledR}$-R film (Ube, Japan), which is derived from 3,3',4,4'-biphenyltetracarboxylic acid dianhydride (BPDA) and ODA. The film with a H/C ratio of 0.0420 showed a flame retardancy level of UL-94 VTM-0 and a LOI higher than 40.0\%. However, when the BPDA was changed to HBPDA, the derived semi-alicyclic CPI films with the $\mathrm{H} / \mathrm{C}$ ratio of 0.0779 showed a reduced LOI of $21.5 \%$, which is a combustible material [26]. Thus, it can be deduced that introduction of alicyclic units into PI films inevitably deteriorate the flame retardancy of the PI films. Enhancement of the flame retardancy of the semi-alicyclic CPI films has been becoming one of the most important issues for expanding the applications of the films in electrical, electronic, and other high-tech fields. However, it is greatly challenging to achieve this goal because it should maintain the excellent optical properties and thermal stability while endowing the semi-alicyclic CPI films good flame retardancy. This greatly limits the application of traditional flame retardant procedures for polymer films. To the best of our knowledge, there are few reports in the literature on the flame retardancy enhancement for semi-alicyclic CPI films up to now. There are also few reports on the industrial-scale production of flame retardant semi-alicyclic CPI films up to now.

In the current work, a series of CPI films with enhanced flame retardancy were developed. Phenoxysubstituted oligomeric polyphosphazene (PPZ) was used as the flame retardant and combined with the CPI matrix derived from 1,2,4,5-cyclohexane tetracarboxylic dianhydride (CHDA) and ODA. The effects of the PPZ fillers on the thermal properties, optical properties, and flame retardancy of the composite films were investigated in detail. At last, on the basis of the laboratory research work, the continuous manufacturing of the typical CPI/PPZ composite film was also carried out. 


\section{Experimental section}

\subsection{Materials}

1,2,4,5-Cyclohexanetetracarboxylic dianhydride (CHDA) was purchased from Newera Kesense New Materials Co. Ltd. (Weihai, Shandong, China) and dried at $180^{\circ} \mathrm{C}$ in vacuo for $12 \mathrm{~h}$ prior to use. $4,4^{\prime}$ Oxydianiline (ODA) was purchased from Wakayama Seika Kogyo Co., Ltd. (Wakayama, Japan) and used as received. Phenoxy-substituted oligomeric polyphosphazene (PPZ) was purchased from Fushimi Pharmaceutical Co. Ltd. (Kagawa, Japan) with the trademark of Rabitle ${ }^{\circledR}$ FP100. Electronic grade $\gamma$-butyrolactone (GBL) was purchased from Hangzhou Greenda Chem. Co. Ltd. (Hangzhou, China) and used as received. Polar aprotic solvents, including $N$-methyl-2-pyrrolidinone (NMP), $N, N$-dimethylacetamide (DMAc) and $N, N$-dimethylformamide (DMF) were purchased from Sigma-Aldrich China (Shanghai, China) and further purified by distillation prior to use. The other commercially available reagents were used without further purification.

\subsection{Measurements}

Attenuated total reflectance Fourier transform infrared (ATR-FTIR) spectrum was obtained on a Bruker Tensor-27 FT-IR spectrometer (Ettlingen, Germany). The number average molecular weight $\left(M_{\mathrm{n}}\right)$ and weight average molecular weight $\left(M_{\mathrm{w}}\right)$ of the PI resins were measured using a gel permeation chromatography (GPC) system (Shimadzu, Kyoto, Japan) with a LC-20AD dual-plunger parallel-flow pumps (D1-LC), a SIL-20A is a total-volume injection-type autosampler, a CTO-20A column oven, and a RID-20A detector. HPLC grade NMP was used as the mobile phase at a flow rate of $1.0 \mathrm{ml} / \mathrm{min}$. Wide-angle X-ray diffraction (XRD) was conducted on a Rigaku D/max-2500 X-ray diffractometer (Tokyo, Japan) with $\mathrm{Cu}-\mathrm{K} \alpha 1$ radiation, operated at $40 \mathrm{kV}$ and $200 \mathrm{~mA}$. X-ray photoelectron spectroscopy (XPS) data were obtained with an ESCALab220i-XL electron spectrometer (Thermo Fisher Scientific, Massachusetts, USA) using $300 \mathrm{~W}$ of $\mathrm{MgK} \alpha$ radiation. The base pressure was $3 \cdot 10^{-9} \mathrm{mbar}$. The binding energies were referenced to the $\mathrm{C} 1 \mathrm{~s}$ line at $284.8 \mathrm{eV}$ from the adventitious carbon. Ultraviolet-visible (UV-Vis) spectra were recorded on a Hitachi U-3210 spectrophotometer (Tokyo, Japan) at room temperature. Yellow index (YI) values of the PI fabrics or films were measured using an X-rite color i7 spectrophotometer (Michigan, USA) with
PI samples at a thickness of $50 \mu \mathrm{m}$ in accordance with the procedure described in ASTM D1925. The color parameters were calculated according to a CIE Lab equation. $L^{*}$ is the lightness, where 100 means white, and 0 implies black. A positive $a^{*}$ means a red color, and a negative one indicates a green color. A positive $b^{*}$ means a yellow color, and a negative one indicates a blue color. Differential scanning calorimetry (DSC) and thermogravimetric analysis (TGA) were recorded on a TA-Q100 and TA-Q50 thermal analysis system (Delaware, USA) at a heating rate of $10^{\circ} \mathrm{C} / \mathrm{min}$ in nitrogen, respectively. The tensile properties were performed on an Instron 3365 Tensile Apparatus (Norwood, MA, USA) with $80 \times 10 \times 0.05 \mathrm{~mm}^{3}$ samples in accordance with GB/T 1040.3-2006 at a drawing rate of $2.0 \mathrm{~mm} / \mathrm{min}$. At least six test samples were tested for each PI film, and results were averaged.

The limiting oxygen index (LOI) tests were carried out according to the standard of GB/T 2406.2-2009 or ISO 4589-2: 2017. The test specimens were $160 \pm 5 \mathrm{~mm}$ in length, $20.0 \pm 0.3 \mathrm{~mm}$ in width, and the thickness was $20 \pm 1 \mu \mathrm{m}$. The PI samples were pretreated at $23{ }^{\circ} \mathrm{C}$ under a relative humidity of $50 \%$ for $120 \mathrm{~h}$ in a conditioning chamber. The temperature in the laboratory during the measurement was $23^{\circ} \mathrm{C}$, and the relative humidity was $35 \%$. Each of the samples was flamed with a gas burner for no longer than 10 seconds. The gas flow was set to $10 \mathrm{l} / \mathrm{min}$. For each composition, 10 samples were used in one measurement series.

The UL 94 VTM (Underwriters Laboratories Incorporated, Vertical Thin Material) tests were carried out according to the standard of UL 94 or ISO 9773: 1999. The test specimens were $125 \pm 2 \mathrm{~mm}$ in length, $30.0 \pm 0.3 \mathrm{~mm}$ in width, and the thickness was $20 \pm 1 \mu \mathrm{m}$. The PI samples were pretreated at $23^{\circ} \mathrm{C}$ under a relative humidity of $50 \%$ for $48 \mathrm{~h}$ in a conditioning chamber and then aged at $70^{\circ} \mathrm{C}$ in a hot air oven for $168 \mathrm{~h}$. Each of the samples was flamed with a gas burner for 3 seconds twice with the flame height of $20 \mathrm{~mm}$. The second flame application time begins as soon as the first burning time ends. For each composition, 10 samples were used in one measurement series. The burning time of each individual test specimen, including after first $\left(t_{1}\right)$ and second $\left(t_{2}\right)$ flame applications, were recorded.

The flaming behavior of the PI composite films was investigated using an FTT0007 cone calorimeter (Fire Testing Technology, West Sussex, UK) according to 
the standard of ASTM E1354-2015. The size of the PI films was $100 \mathrm{~mm} \times 100 \mathrm{~mm} \times 0.05 \mathrm{~mm}$ (length $\times$ width $\times$ thickness). The PI samples were wrapped in an aluminum foil and exposed horizontally to $50 \mathrm{~kW} / \mathrm{m}^{2}$ external heat flux. The total heat release (THR), heat release rate (HRR), total smoke production (TSP), smoke production rate (SPR), and rate of smoke release (RSR) of the PI films were recorded. The micro-morphologies of the combusted PI films were investigated using a Technex Lab Tiny-SEM 1540 field emission scanning electron microscopy (SEM) (Tokyo, Japan) with an accelerating voltage of $15 \mathrm{kV}$ for imaging. $P_{\mathrm{t}} / P_{\mathrm{d}}$ was sputtered on each film in advance of the SEM measurements.

\subsection{Polyimides preparation}

The CPI film matrix (PI-a) was synthesized from CHDA and ODA via a one-step high-temperature polycondensation procedure. Into a $500 \mathrm{ml}$ threenecked, round-bottomed flask equipped with a mechanical stirrer, heating equipment, a Dean-Stark trap, and a nitrogen inlet was charged with ODA $(20.0240 \mathrm{~g}, 100 \mathrm{mmol})$ and $\mathrm{GBL}(100.0 \mathrm{~g})$ at room temperature $\left(25^{\circ} \mathrm{C}\right)$. Then, to the clear diamine solution, CHDA (22.4170 g, $100 \mathrm{mmol}$ ) was added in one batch, and an additional volume of GBL (27.3 g) was added to wash the residual dianhydride, and at the same time to adjust the solid content of the reaction system to be $25 \mathrm{wt} \%$. After stirring in nitrogen for $1 \mathrm{~h}$, the toluene dehydrating agent $(200 \mathrm{ml})$ and the triethylamine catalyst $(1.0 \mathrm{~g})$ was added. The reaction mixture was then heated to $180^{\circ} \mathrm{C}$ to facilitate the imidization reaction, during which the water byproducts were distilled out of the reaction system via the toluene azeotrope at $130 \sim 140^{\circ} \mathrm{C}$ for $6 \mathrm{~h}$. The high-temperature imidization reaction continued at $180^{\circ} \mathrm{C}$ for $3 \mathrm{~h}$, and then cooled to room temperature. The obtained pale-brown and viscous solution was slowly dripped into an excess of aqueous ethanol solution (ethanol $/$ water $=80 / 20$, volume ratio). The precipitated fibrous PI-a resin was collected and dried at $80^{\circ} \mathrm{C}$ under vacuum for $24 \mathrm{~h}$. PI-a was obtained as a white fibrous resin. Yield: $37.68 \mathrm{~g}(97 \%)$. The fully dried PI-a resin was dissolved into DMAc at a solid content of $20 \mathrm{wt} \%$ to obtain the PI solution. The solution was stirred at room temperature overnight and then filtered through a $0.25 \mu \mathrm{m}$ Teflon syringe filter to remove any impurities. The purified PI-a varnish was used for film preparation. Colorless and transparent PI-a film was obtained by thermally baking the solution in a nitrogen flow according to the following heating procedure: $80^{\circ} \mathrm{C} / 2 \mathrm{~h}, 150^{\circ} \mathrm{C} / 1 \mathrm{~h}, 200^{\circ} \mathrm{C} / 1 \mathrm{~h}$, $250^{\circ} \mathrm{C} / 1 \mathrm{~h}$, and $280^{\circ} \mathrm{C} / 1 \mathrm{~h}$.

The CPI/FP100 composite films (PI-b PI-f) were prepared by physically blending the PI-a/DMAc matrix and the FP100/DMAc solution at a solid content of $20 \mathrm{wt} \%$. As an example, PI-b (CHDA-ODAFP100-5) with the $5 \mathrm{wt} \%$ FP100 in the film was prepared as follows. Into a $250 \mathrm{ml}$ three-necked, roundbottomed flask equipped with a mechanical stirrer and a nitrogen inlet was charged with PI-a resin (10.0 g) and newly distilled DMAc (37.1 g). The resin solution was stirred at room temperature $\left(25^{\circ} \mathrm{C}\right)$ for $3 \mathrm{~h}$ to afford a transparent and viscous solution $\mathrm{A}$. Simultaneously, FP100 (0.5263 g) was dissolved into DMAc $(5.0 \mathrm{~g})$ at room temperature to afford solution B. Then, to the clear solution A, solution B was added, and the mixture was mechanically stirred at a speed of $600 \mathrm{rpm}$ for $2 \mathrm{~h}$. Then, the obtained viscous solution was defoamed and then cast onto a clean glass substrate. The solution was thermally baked in a nitrogen flow according to the following procedure: $80^{\circ} \mathrm{C} / 2 \mathrm{~h}, \quad 150^{\circ} \mathrm{C} / 1 \mathrm{~h}, \quad 200^{\circ} \mathrm{C} / 1 \mathrm{~h}$, $250^{\circ} \mathrm{C} / 1 \mathrm{~h}$, and $280^{\circ} \mathrm{C} / 1 \mathrm{~h}$. Free-standing PI-b film was obtained by immersion the cooled glass plate into deionized water.

The other PI composite films, including PI-c (CHDA-ODA-FP100-10), PI-d (CHDA-ODAFP100-15), PI-e (CHDA-ODA-FP100-20), and PI-f (CHDA-ODA- FP100-25) were prepared according to a similar procedure as mentioned above.

\section{Results and discussion}

\subsection{Polyimide preparation}

The CPI matrix PI-a (CHDA-ODA) was prepared by a well-established route for semi-alicyclic PI, as shown in Figure 1. According to the GPC measurements, the PI-a resin showed a numerical average molecular weight $\left(M_{\mathrm{n}}\right)$ and a weight average molecular weight $\left(M_{\mathrm{w}}\right)$ of $1.5 \cdot 10^{5}$ and $2.7 \cdot 10^{5} \mathrm{~g} / \mathrm{mol}$, respectively, indicating the high reactivity of the CHDA dianhydride at high temperature. In addition, the PI-a resin showed the narrow polydispersity indices (PDI) of 1.75. The PI-a resin was soluble in polar aprotic solvents, including NMP, DMAc, DMF, and GBL. PPZ (FP-100) was selected as the flame retardant (FR) from various candidates due to the well combined properties. First, FP100 is highly soluble in the good solvents, such as DMAc for PI-a matrix; thus, it could be dispersed into the PI matrix with 


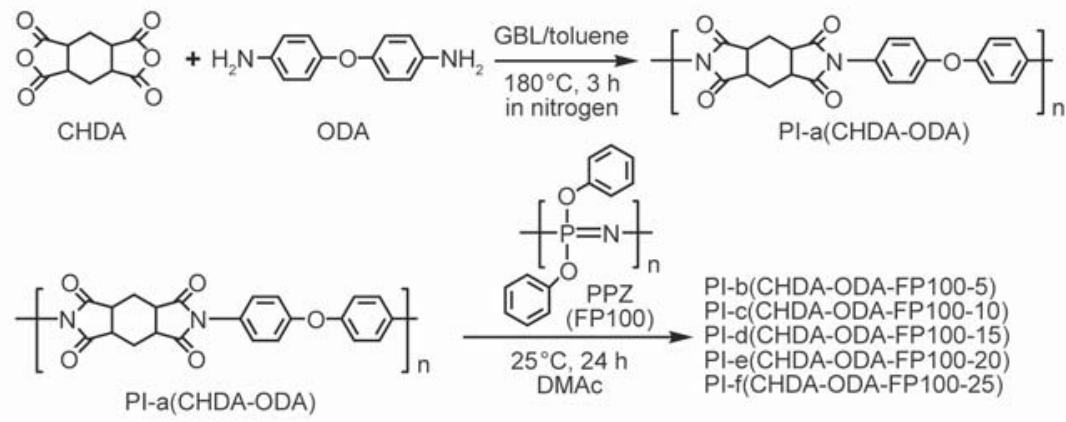

Figure 1. Preparation of CPI/PPZ composite films.

Table 1. Formulation of the PI films.

\begin{tabular}{|l|c|c|c|}
\hline \multicolumn{1}{|c|}{ PI } & $\begin{array}{c}\text { Solution A } \\
\text { (PI [g]/DMAc }[\mathbf{g}] \mathbf{)}\end{array}$ & $\begin{array}{c}\text { Solution B } \\
\text { (FP100 [g]/DMAc }[\mathbf{g}])\end{array}$ & $\begin{array}{c}\text { Contents of FP100 in PI film } \\
\text { [wt\%] }\end{array}$ \\
\hline PI-a & $10.0 / 40.0$ & 0 & 0 \\
\hline PI-b & $10.0 / 37.1$ & $0.5263 / 5.0$ & 5 \\
\hline PI-c & $10.0 / 39.4$ & $1.1111 / 5.0$ & 10 \\
\hline PI-d & $10.0 / 42.1$ & $1.7647 / 5.0$ & 15 \\
\hline PI-e & $10.0 / 40.0$ & $2.5000 / 5.0$ & 20 \\
\hline PI-f & $10.0 / 43.3$ & $3.3333 / 5.0$ & 25 \\
\hline
\end{tabular}

quite a low degree of aggregation. The introduction of FP100 is expected to have little effects on the optical transparency of the composite films. Secondly, FP100 showed good thermal stability with the initial thermal decomposition temperature higher than $350{ }^{\circ} \mathrm{C}$; thus could maintain the intrinsic thermal stability of the PI-a matrix. The CPI/PPZ composite films (PI-b PI-f) were then prepared by physically blending the PI-a matrix with FP100 filler in DMAc, according to the formulation listed in Table 1.

The chemical structure of the PI films was confirmed, and the ATR-FTIR spectra of the PI films together with the FP100 are shown Figure 2. First, the characteristic absorptions of imide rings, including the asymmetrical and symmetrical stretching vibrations

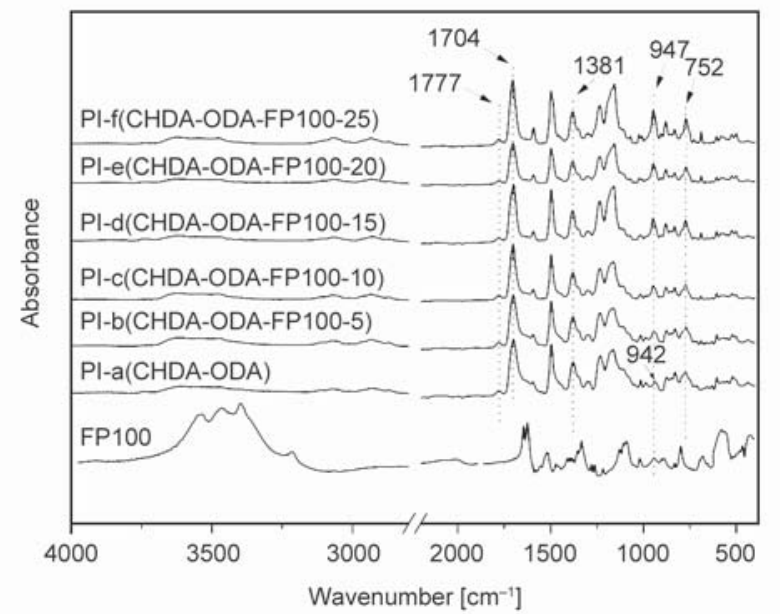

Figure 2. ATR-FTIR spectra of CPI/PPZ composite films. of imide carbonyl at 1777 and $1704 \mathrm{~cm}^{-1}$, respectively, the absorptions of imide $\mathrm{C}-\mathrm{N}$ bonds at $1381 \mathrm{~cm}^{-1}$, and the absorptions of imide ring deformation at $752 \mathrm{~cm}^{-1}$ were all clearly observed for PI-b PI-f [27]. Meanwhile, the characteristic absorptions of saturated $\mathrm{C}-\mathrm{H}$ bonds in $\mathrm{CHDA}$ unit for PI-b PI-f were also detected in the wavenumber range of 2800$3000 \mathrm{~cm}^{-1}$. Secondly, the characteristic absorptions of $\mathrm{P}-\mathrm{O}-\mathrm{C}$ bonds at $947 \mathrm{~cm}^{-1}$ and $\mathrm{P}=\mathrm{N}$ bonds at $1197 \mathrm{~cm}^{-1}$ could be observed in all of the spectra expect that of PI-a, indicating the successful incorporation of FP100 in the composite films.

The successful incorporation of FP100 into the PI-a matrix could also be further confirmed by XPS and XRD measurements. It can be seen from the XPS spectra (Figure 3) of the PI films that the absorptions of $\mathrm{O} 1 \mathrm{~s}, \mathrm{~N} 1 \mathrm{~s}$, and $\mathrm{C} 1 \mathrm{~s}$ could be observed for all of the samples, whereas those of the P2p could only be recorded in the spectra of PI-b PI-f. This proves the successful combination of the FP100 FR into the PI-a matrix. In the XRD spectra of the PI films together with that of the FP100 shown in Figure 4, typical amorphous features could be confirmed for all of the PI samples in spite of the crystalline nature for the FP100 filler. Nevertheless, it can be clearly observed that the absorptions of the crystalline FP100 gradually appeared in the composite films when the loading amount was higher than $10 \mathrm{wt} \%$ (PI-c). Thus, it can be deduced that phase separation might occur in the composite films of PI-c PI-f, which would 


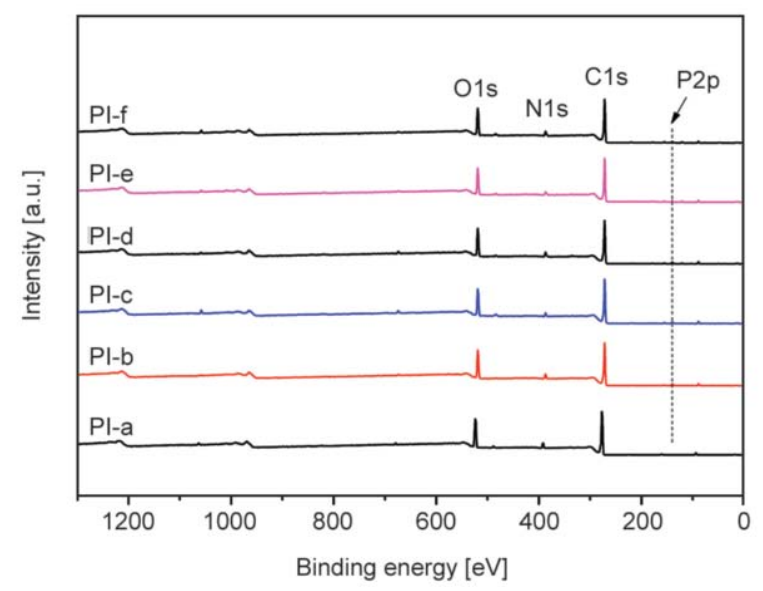

Figure 3. XPS spectra of CPI/PPZ composite films.

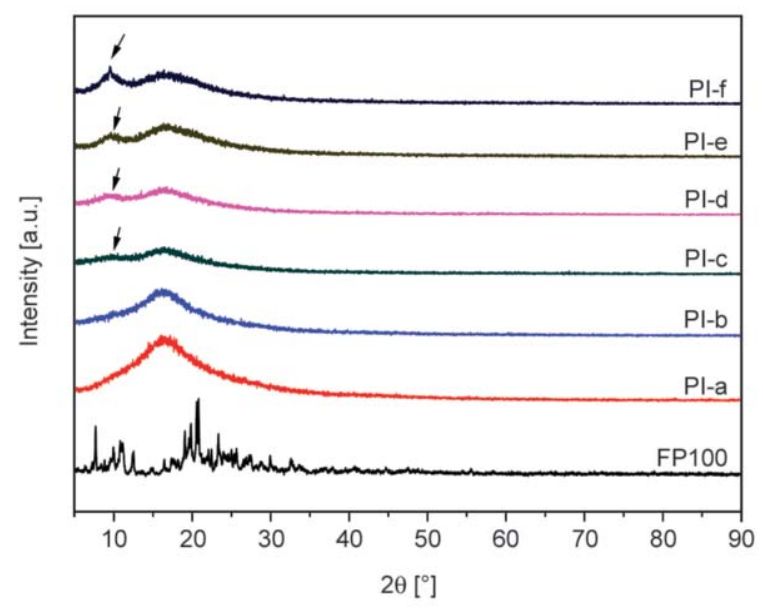

Figure 4. XRD spectra of CPI/PPZ composite films.

inevitably affect the surface micro-morphologies and optical properties of the PI films.

\subsection{Thermal properties}

Effects of the incorporation of FP100 on the thermal stability of the PI composite films were evaluated by the TGA and DSC measurements and the results were tabulated in Table 2. In the practical applications of CPI films in optoelectronic fabrication, good thermal stability is highly preferred due to the diverse hightemperature manufacturing processes. Thus, in the current work, one of the main purposes is to maintain the intrinsic thermal stability of the semi-alicyclic PI film matrix when enhancing the flame retardancy of the polymer. It can be clearly seen from the TGA and derivative thermogravimetry (DTG) plots shown in Figure 5 that this research target was well achieved. As shown in Figure 5a, FP100 filler showed good thermal resistance with the $5 \%$ weight loss temperature $\left(T_{5 \%}\right)$ of $343.8^{\circ} \mathrm{C}$ in nitrogen. Although it is nearly $88^{\circ} \mathrm{C}$ lower than that of the PI-a matrix $\left(T_{5 \%}=431.6^{\circ} \mathrm{C}\right)$, the PI composite films exhibited the $T_{5 \%}$ values in the range of $358.9-404.3^{\circ} \mathrm{C}$ (Table 2). These values are usually high enough for their applications in practice. Interestingly, the PI composite films showed residual weight ratios in the range of $57.7 \sim 61.2 \mathrm{wt} \%$ at $700^{\circ} \mathrm{C}$, which is higher than both of those of the PI-a matrix $\left(R_{\mathrm{w} 700}=\right.$ $37.6 \mathrm{wt} \%)$ and FP100 $\left(R_{\mathrm{w} 600}=8.5 \mathrm{wt} \%\right)$. The higher $R_{\mathrm{w} 70} 0$ values for the PI composite films might be due to the formation of thermal resistant phosphoruscontaining passivation layers between the FP100 filler and the PI matrix. The former provided the phosphorus elements, and the latter provided the oxygen components. As for the low $R_{\mathrm{w} 600}$ values of the FP100, it might be due to the lower molecular weight of the oligomer. The DTG curves of the PI composite films (Figure 5b) revealed the maximum decomposition temperature $\left(T_{\max }\right)$ and rate and the steps of the decomposition of the PI samples. The Tmax values of the PI films and FP100 decreased with the order of PI-a $>$ PI-b $>$ FP100 $>$ PI-c $\approx$ PI-d $>$ PI-e $>$ PI-f. It is clear that the thermal stability of the PI composite films apparently deteriorated when the FP100 loading was higher than $5 \mathrm{wt} \%$ (PI-c $\sim$ PI-f).

Table 2. Thermal and optical properties of CPI/PPZ composite films.

\begin{tabular}{|l|c|c|c|c|c|c|c|c|}
\hline \multicolumn{1}{|c|}{ PI } & \multicolumn{3}{|c|}{ Thermal properties $^{\mathbf{a}}$} & \multicolumn{5}{c|}{ Optical properties $^{\mathbf{b}}$} \\
\hline & $\begin{array}{c}\boldsymbol{T}_{\mathbf{g}} \\
{\left[{ }^{\circ} \mathbf{C}\right]}\end{array}$ & $\begin{array}{c}\boldsymbol{T}_{\mathbf{5 \%}}\left[{ }^{\circ} \mathbf{C}\right] \\
\end{array}$ & $\begin{array}{c}\boldsymbol{R}_{\mathbf{w 7 0 0}} \\
{[\mathbf{\%}]}\end{array}$ & $\begin{array}{c}\boldsymbol{\lambda} \\
{[\mathbf{n m}]}\end{array}$ & $\begin{array}{c}\boldsymbol{T}_{\mathbf{4 0 0}} \\
{[\mathbf{\%}]}\end{array}$ & $\begin{array}{c}\boldsymbol{d} \\
{[\boldsymbol{\mu m}]}\end{array}$ & $\boldsymbol{b}^{\text {* }}$ & $\begin{array}{c}\text { haze } \\
{[\%]}\end{array}$ \\
\hline PI-a & 346.8 & 431.6 & 37.6 & 288 & 77.9 & $25 \pm 0.5$ & 0.67 & 1.79 \\
\hline PI-b & 325.6 & 404.3 & 61.2 & 285 & 83.9 & $25 \pm 0.5$ & 3.28 & 2.14 \\
\hline PI-c & 323.0 & 396.7 & 58.9 & 281 & 85.6 & $25 \pm 0.5$ & 4.16 & 2.23 \\
\hline PI-d & 328.6 & 396.8 & 58.4 & 279 & 85.4 & $25 \pm 0.5$ & 4.98 & 43.19 \\
\hline PI-e & 319.5 & 353.8 & 66.5 & 281 & 68.8 & $25 \pm 0.5$ & 5.65 & 68.17 \\
\hline PI-f & 323.1 & 358.9 & 57.7 & 279 & 68.0 & $25 \pm 0.5$ & 5.84 & 83.44 \\
\hline
\end{tabular}

${ }^{\mathrm{a}} T_{\mathrm{g}}$ : glass-transition temperatures; $T_{5 \%}: 5 \%$ weight loss temperatures; $R_{\mathrm{w} 700}$ : residual weight ratio at $700{ }^{\circ} \mathrm{C}$ in nitrogen;

$\mathrm{b} d$ : thickness of CPI/PPZ composite films; $T_{400}$ : transmittance of the films at the wavelength of $400 \mathrm{~nm} ; b^{*}$ : yellow index. 

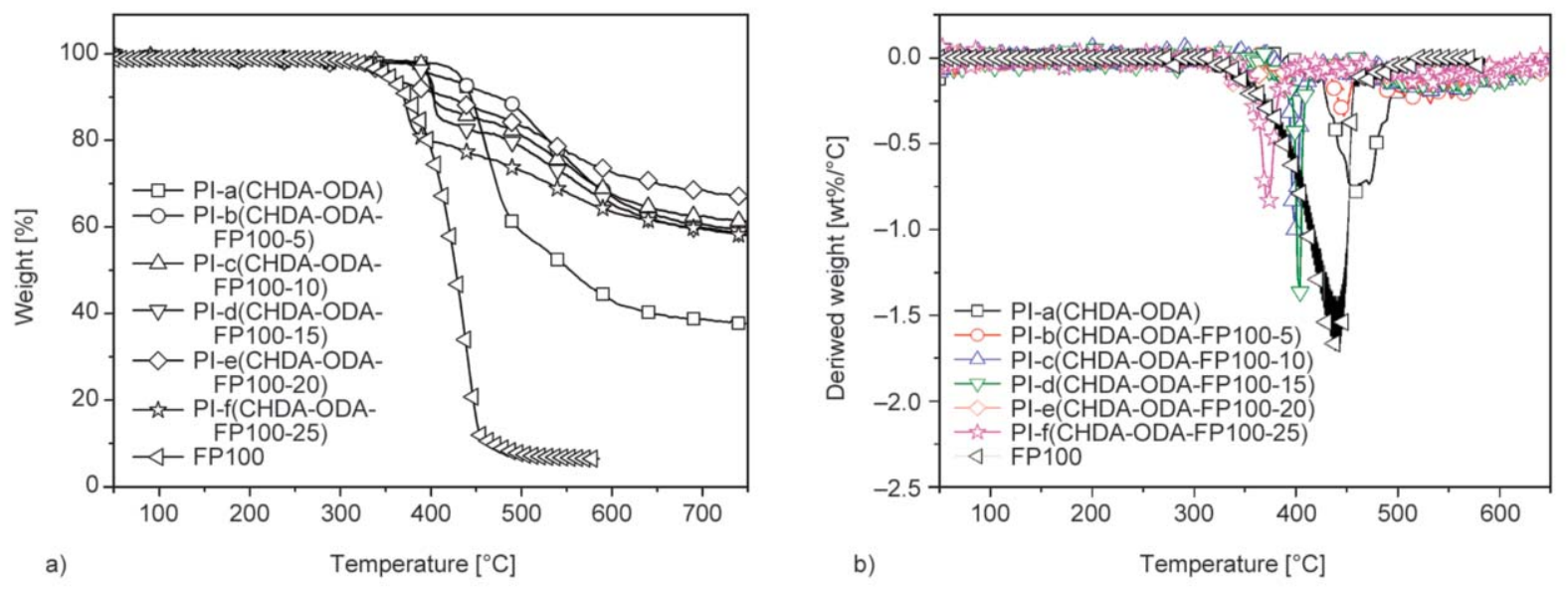

Figure 5. TGA (a) and DTG (b) plots of CPI/PPZ composite films.

The glass transition temperatures $\left(T_{\mathrm{g}} \mathrm{s}\right)$ of the PI films were determined by DSC measurement. It can be seen from Figure 6 that all the PI films exhibited clear glass transition behaviors during the heating from 50 to $400^{\circ} \mathrm{C}$. The PI-a matrix film showed a high glass transition temperature $\left(T_{\mathrm{g}}\right)$ value of $346.8^{\circ} \mathrm{C}$. The incorporation of FP100 filler decreased the $T_{\mathrm{g}}$ values of the PI films. PI-b $\sim$ PI-f composite films $T_{\mathrm{g}}$ values in the range of $319.5 \sim 328.6^{\circ} \mathrm{C}$, depending on the loading amounts of the FP100 fillers. The slightly deteriorated thermal stability of the PI composite films is clearly attributed to the incorporation of FP100 oligomer, which playing as a role of plasticizer. Another important information that could be revealed by the figure is the multi-transition behaviors for PI-e and PI-f films. Clear thermal decomposition peaks could be observed in the temperature range of $350 \sim 400^{\circ} \mathrm{C}$. This is mainly due to the thermal decomposition of the FP100 at elevated temperatures for the high loading amounts of FP100 fillers in these two samples. On the other hand, this is also a clear signal for the loose interactions between the

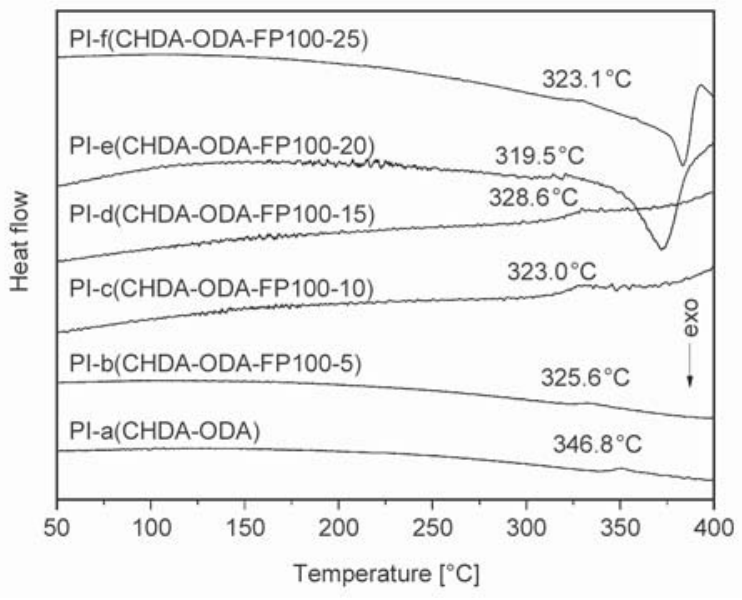

Figure 6. DSC plots of CPI/PPZ films.
FP100 filler and the PI matrix, and phase separation might occur for the PI composite films with higher contents of the filler. Nevertheless, the $T_{\mathrm{g}}$ values higher than $300^{\circ} \mathrm{C}$ could guarantee the practical applications of the current PI composite films in most of the industrial fields.

\subsection{Optical properties}

It is one of our most important targets to enhance the flame retardancy of the PI-a(CHDA-ODA) film while maintaining the intrinsic good optical properties, including high optical transmittance in the UV-Vis light region. It could be deduced from the XRD (Figure 4) measurements mentioned above that over the incorporation of FP100 might induce the phase separation of the filler and the matrix, thus deteriorating the optical properties of the PI composite films. In order to evaluate the effects of FP100 on the optical properties of the PI films, UV-Vis and CIE Lab parameters of the PI films were detected. Figure 7 shows the UV-Vis spectra of the PI films at a thickness of around $25 \mu \mathrm{m}$ together with the inserted appearance of the films, and the optical parameters are summarized in Table 2. PI-a matrix film showed good optical transparency with the UV cutoff wavelength of $288 \mathrm{~nm}$ and the transmittances of $77.9 \%$ at the wavelength of $400 \mathrm{~nm}$. The good optical transparency of the semi-alicyclic PI-a film is mainly attributed to the reduced intra- and inter-molecular charge transfer (CT) interactions between the electron-donating ODA moiety and the electron-accepting CHDA moiety. The non-conjugated cyclohexane structure in the dianhydride unit apparently decreased the electron-accepting ability of the dianhydride unit [28]. Interestingly, the incorporation of FP100 fillers increased the optical transmittance values of the PI 


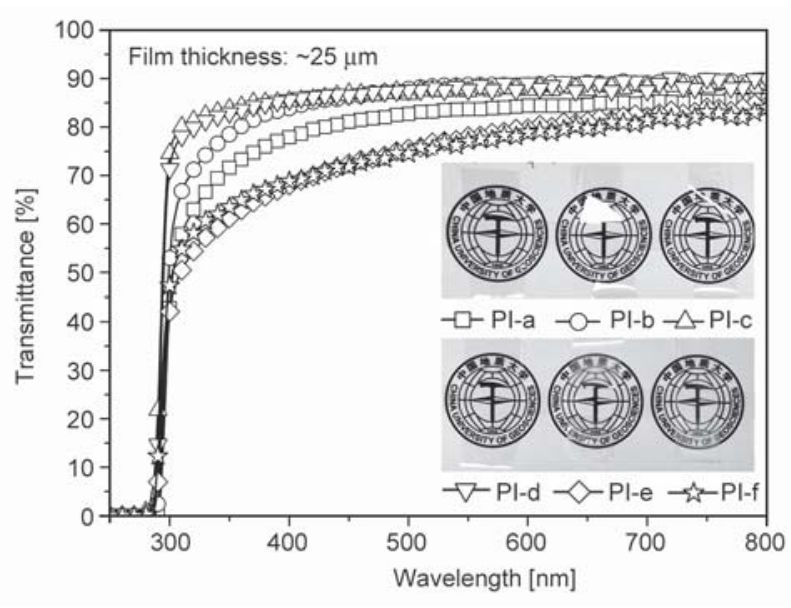

Figure 7. UV-Vis spectra of CPI/PPZ films. Insert: appearance of PI films.

composite films at $400 \mathrm{~nm}\left(T_{400}\right)$ when the loading contents were lower than $15 \mathrm{wt} \%$. For example, the $T_{400}$ values of the PI films increased with the order of PI-a $(77.9 \%)<$ PI-b $(83.9 \%)<$ PI-c $(85.6 \%) \approx<$ PI-d (85.4\%). When the loading amount of FP100 was higher than $15 \mathrm{wt} \%$, the optical transmittance of the composite films deteriorated sharply. PI-e and PI-f films showed $T_{400}$ value of 68.8 and $68.0 \%$, respectively, indicating the obvious phase separation of the filler and the matrix.

The effects of overloading of FP100 on the optical properties of the PI composite films could also be observed by the CIE Lab measurements shown in Table 2. The yellow indices $\left(b^{*}\right)$ of the PI films gradually increased from the initial of 0.67 for PI-a matrix to 5.84 of the PI-f film, indicating the trends of yellowness with the increasing contents of the FP100 filler in the composite films. Haze investigation results revealed that the degree of opaqueness of the films increased sharply when the content of the FP100 was higher than $10 \mathrm{wt} \%$. The haze values of the PI films increased with the order of PI-a $(1.79 \%)<$
PI-b $(2.14 \%)<$ PI-c $(2.23 \%)<$ PI-d $(43.19 \%)<$ PI-e $(68.17 \%)<$ PI-f $(83.44 \%)$. Thus, based on the CIE Lab optical parameter measurements, only PI-a, PI-b, and PI-c films possess the practicability for optoelectronic applications. Only these three films were selected for the following flame retardancy evaluation.

\subsection{Flame retardancy}

The effects of the incorporation of FP100 FR on the flame retardancy of the PI films were evaluated by LOI, UL94, and cone calorimetry measurements, respectively and the data are listed in Table 3 . First, as for the LOI tests, PI-a(CHDA-ODA) matrix film is combustible with a low LOI value of $27.4 \%$; however, incorporation of FP100 greatly increased the LOI values of the PI composite films. PI-b(CHDA-ODAFP100-5) and PI-c(CHDA-ODA-FP100-10) films showed LOI values of 41.2 and $46.8 \%$, respectively, indicating nonflammable nature for the composite films. For these two composite films, a UL-94 rating of VTM-0 was obtained with no dripping observed, and self-extinguished behaviors $\left(t_{1}+t_{2} \leq 4 \mathrm{~s}\right)$ were observed after the burner was removed, indicating the high flame resistance of the composite films. The efficacy of prepared PI composite films is obviously higher than those of the other polymer systems containing the similar PPZ FRs. For example, the polylactic acid (PLA)/PPZ composites with enhanced flame retardancy were reported recently [29]. The pristine PLA is susceptible to ignition with an LOI value of $21.0 \%$. The PLA/PPZ composites containing $5 \mathrm{wt} \%$ of PPZ showed an increased LOI value of $26.5 \%$ and a flame retardant class of UL 94-V0. The LOI value $(26.5 \%)$ of the PLA/PPZ composite is much lower than that of the current PI-b (LOI = $41.2 \%$ ) containing the same loading ratio of PPZ FR.

Table 3. Flame retardant data of CPI/PPZ composite films.

\begin{tabular}{|c|c|c|c|c|c|c|c|c|c|c|}
\hline \multirow[b]{2}{*}{ PI } & \multirow{2}{*}{$\begin{array}{c}\text { LOI }^{\mathbf{a}} \\
{[\%]}\end{array}$} & \multicolumn{4}{|c|}{ UL-94 } & \multicolumn{5}{|c|}{ Cone calorimetry } \\
\hline & & level & $\begin{array}{l}t_{1} \\
{[\mathrm{~s}]}\end{array}$ & $\begin{array}{l}t_{2} \\
{[\mathrm{~s}]}\end{array}$ & $\begin{array}{c}t_{1}+t_{2} \\
{[\mathrm{~s}]}\end{array}$ & $\begin{array}{c}T_{H} R^{\mathrm{b}} \\
{\left[\mathrm{MJ} / \mathrm{m}^{2}\right]}\end{array}$ & $\begin{array}{c}p^{p H R R^{\mathrm{c}}} \\
{\left[\mathrm{kW} / \mathrm{m}^{2}\right]}\end{array}$ & $\begin{array}{l}T S P^{\mathrm{d}} \\
{\left[\mathrm{m}^{2}\right]}\end{array}$ & $\begin{array}{l}p S P R^{\mathrm{e}} \\
{\left[\mathrm{m}^{2} / \mathrm{s}\right]}\end{array}$ & $\begin{array}{c}p R S R^{\mathrm{f}} \\
{\left[\left(\mathrm{m}^{2} / \mathbf{s}\right) / \mathbf{m}^{2}\right]}\end{array}$ \\
\hline PI-a & 27.4 & $<$ VTM-2 & $\mathrm{ND}^{\mathrm{g}}$ & ND & ND & 0.82 & 53.17 & 0.18 & 0.0245 & 2.7733 \\
\hline PI-b & 41.2 & VTM-0 & 4 & 0 & 4 & 0.23 & 4.81 & 0.03 & 0.0023 & 0.2640 \\
\hline PI-c & 46.8 & VTM-0 & 0 & 0 & 0 & 0.16 & 2.79 & 0.07 & 0.0026 & 0.3010 \\
\hline
\end{tabular}

${ }^{\text {aL }}$ imited oxygen index;

${ }^{\mathrm{b}}$ Total heat release;

'Peak of heat release rate;

${ }^{\mathrm{d}}$ Total smoke production;

'Peak of smoke production rate;

fPeak of rate of smoke release;

got detected. 
The flame resistance of PI composite films is further evaluated by cone calorimetry measurements. Figure 8 presents the plots of total heat release (THR), heat release rate $(H R R)$, total smoke production (TSP), and smoke production rate $(S P R)$ for the PI films and the combustion data are showed in Table 3. In Figure 8a, the PI-b and PI-c composite films showed total reduced $T H R$ values of 0.23 and $0.16 \mathrm{MJ} / \mathrm{m}^{2}$ during the whole combustion process, respectively, which were apparently lower than that of PI-a matrix $\left(T H R=0.82 \mathrm{MJ} / \mathrm{m}^{2}\right)$. In Figure $8 \mathrm{~b}$, the $H R R$ plots of PI-a matrix film showed a sharp peak with a $\mathrm{p} H R R$ value of $53.17 \mathrm{~kW} / \mathrm{m}^{2}$, while the PI-b and PI-c showed the reduced $p H R R$ values of 4.81 and $2.79 \mathrm{~kW} / \mathrm{m}^{2}$, respectively. The reduced $T H R$ and $p H R R$ values of the CPI/PPZ composite films are mainly attributed to that the phosphorous free radicals formed from the early degradation of $\mathrm{P}=\mathrm{N}$ groups in FP100 effectively quenched the $\mathrm{H} \bullet$ and $\mathrm{OH} \bullet$ radicals $[30,31]$; thus inhibiting the flame in the gas phase during combustion.

As for the smoke release behaviors of the CPI/PPZ composite films, Figure $8 \mathrm{c}$ and Figure $8 \mathrm{~d}$ illustrate the TSP and SPR plots of the PI-b and PI-c composite
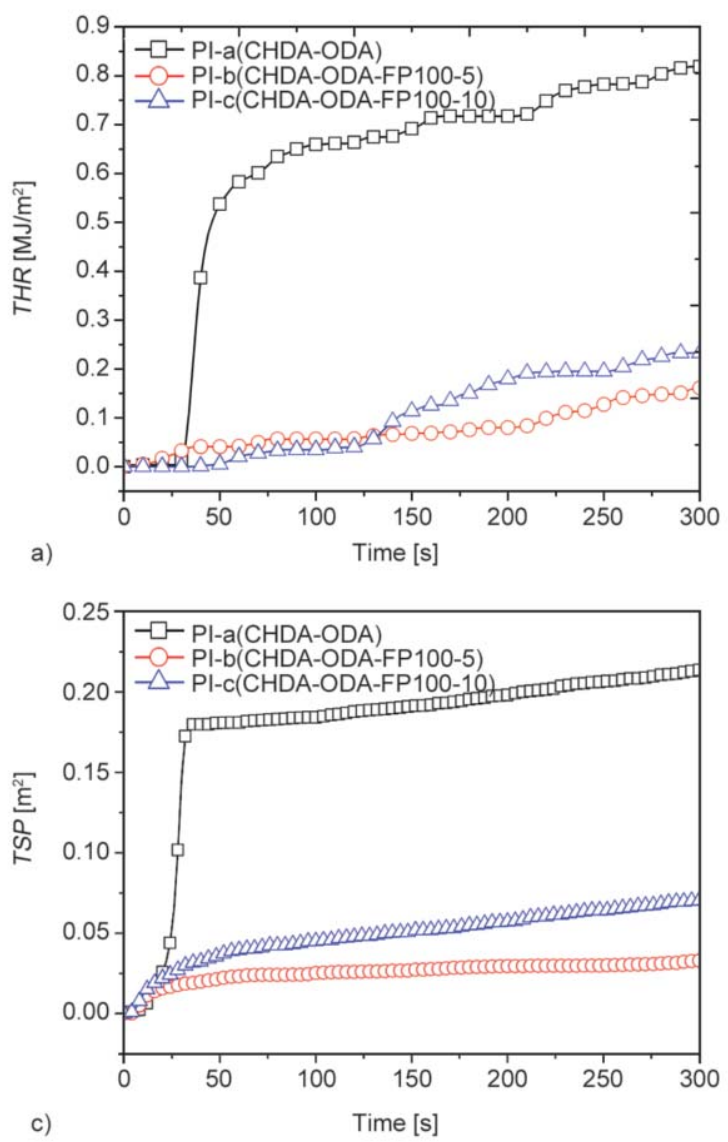

films, respectively. In Figure 8c, the composite films showed TSP values of $0.03 \mathrm{~m}^{2}$ for PI-b and $0.07 \mathrm{~m}^{2}$ for PI-c during the whole combustion process, which were obviously lower than that of the pristine PI-a matrix $\left(T S P=0.18 \mathrm{~m}^{2}\right)$. In Figure 8d, the $S P R$ plots of PI-a film showed a sharp peak with a $p S P R$ value of $0.0245 \mathrm{~m}^{2} / \mathrm{s}$, while the composite films showed a reduced $p S P R$ value of $0.0023 \mathrm{~m} 2 / \mathrm{s}$ for PI-b and $0.0026 \mathrm{~m}^{2} / \mathrm{s}$ for PI-c, which was about an order of magnitude lower than that of PI-a matrix. In addition, PI-b and PI-c composite films showed a peak of rate of smoke release $(R S R)$ value of 0.2640 and $0.3010\left(\mathrm{~m}^{2} / \mathrm{s}\right) / \mathrm{m}^{2}$ during the combustion process, respectively (Table 3 ), which was also nearly an order of magnitude lower than that of PI-a matrix $\left(p R S R=2.7733\left(\mathrm{~m}^{2} / \mathrm{s}\right) / \mathrm{m}^{2}\right)$. The excellent smoke suppression feature of the PI composite films is, on the one hand, owing to the intrinsically low aromatic contents in the semi-alicyclic PI films. On the other hand, it could be ascribed to the charring effect of FP100, which delayed the diffusion of pyrolysis components and protected the unburned substances inside from exposure to the fire [32].
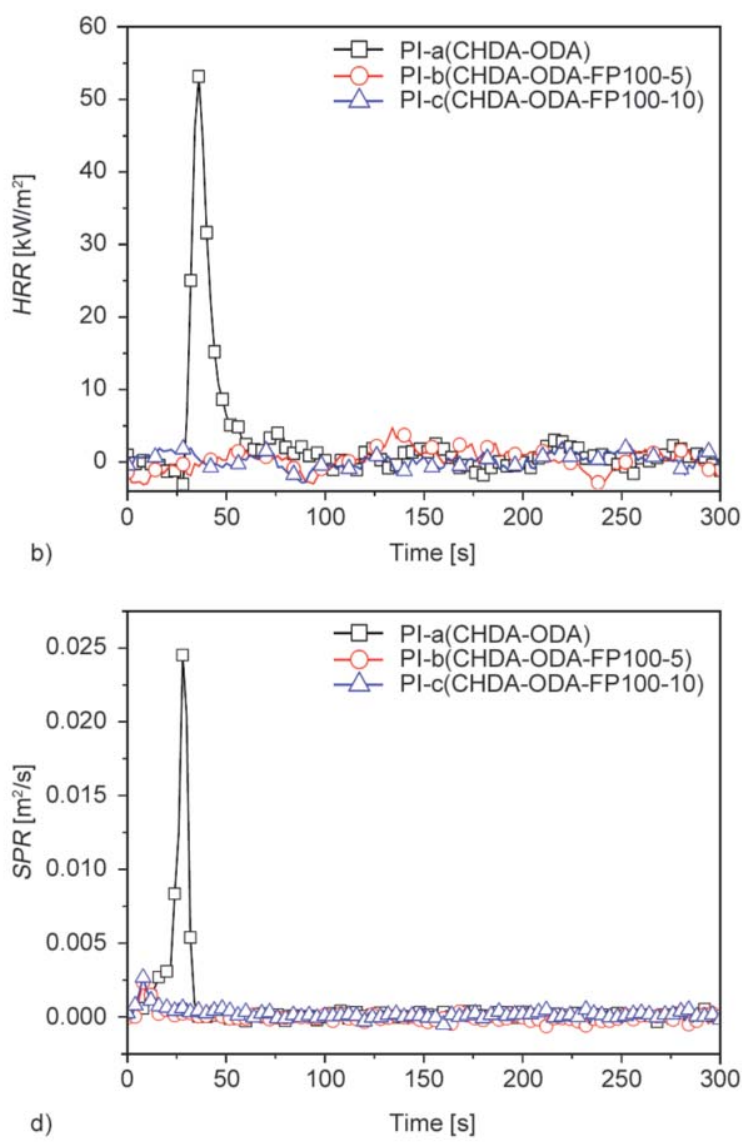

Figure 8. Combustion plots of CPI/PPZ composite films. (a) THR; (b) HRR; (c) TSP; (d) SPR. 
The char residues of PI films after combustion were analyzed in order to reveal the flame retardant mechanism and Figure 9 shows SEM images of the char residues together with the energy dispersive X-ray (EDX) analysis. It can be seen that the content of phosphorus in the char residues of PI-b (Figure 9b) and PI-c (Figure 9c), containing $5 \mathrm{wt} \%$ FP100 and $10 \mathrm{wt} \%$ FP100, respectively, increased gradually. It indicates that during the combustion process, phosphorus could migrate to the external char layer and accumulated in the condensed phase, which could promote to form a compact and thick barrier to delay heat and mass transfer. This is highly consistent with the THR measurements shown in Figure 8a. The THR values of the PI composite films dramatically decreased as the content of FP100 increased, which is mainly attributed to the earlier decomposition of the FP100 FR to form a char barrier on the surface of the PI-b and PI-c composite films.

In summary, as for the heat release behaviors revealed the cone calorimetry measurements, the $T H R$ was reduced by $72.0 \%$ for PI-b and $80.5 \%$ for PI-c. As for the smoke release behaviors, the TSP was reduced by $83.3 \%$ for PI-b and $61.1 \%$ for PI-c. Phosphorus can function both in the gas phase and condensed phase, and on the one hand, quenched the $\mathrm{H} \bullet$ and $\mathrm{OH} \bullet$ radicals, and on the other hand promoted char formation on the surface of composite films,
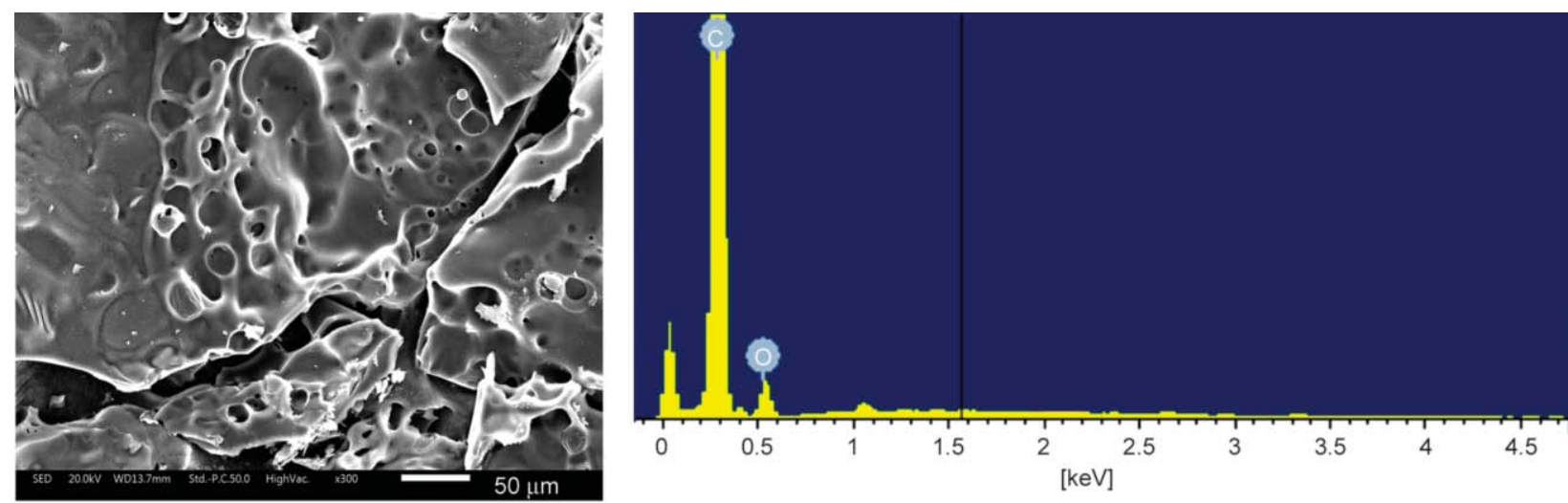

a)
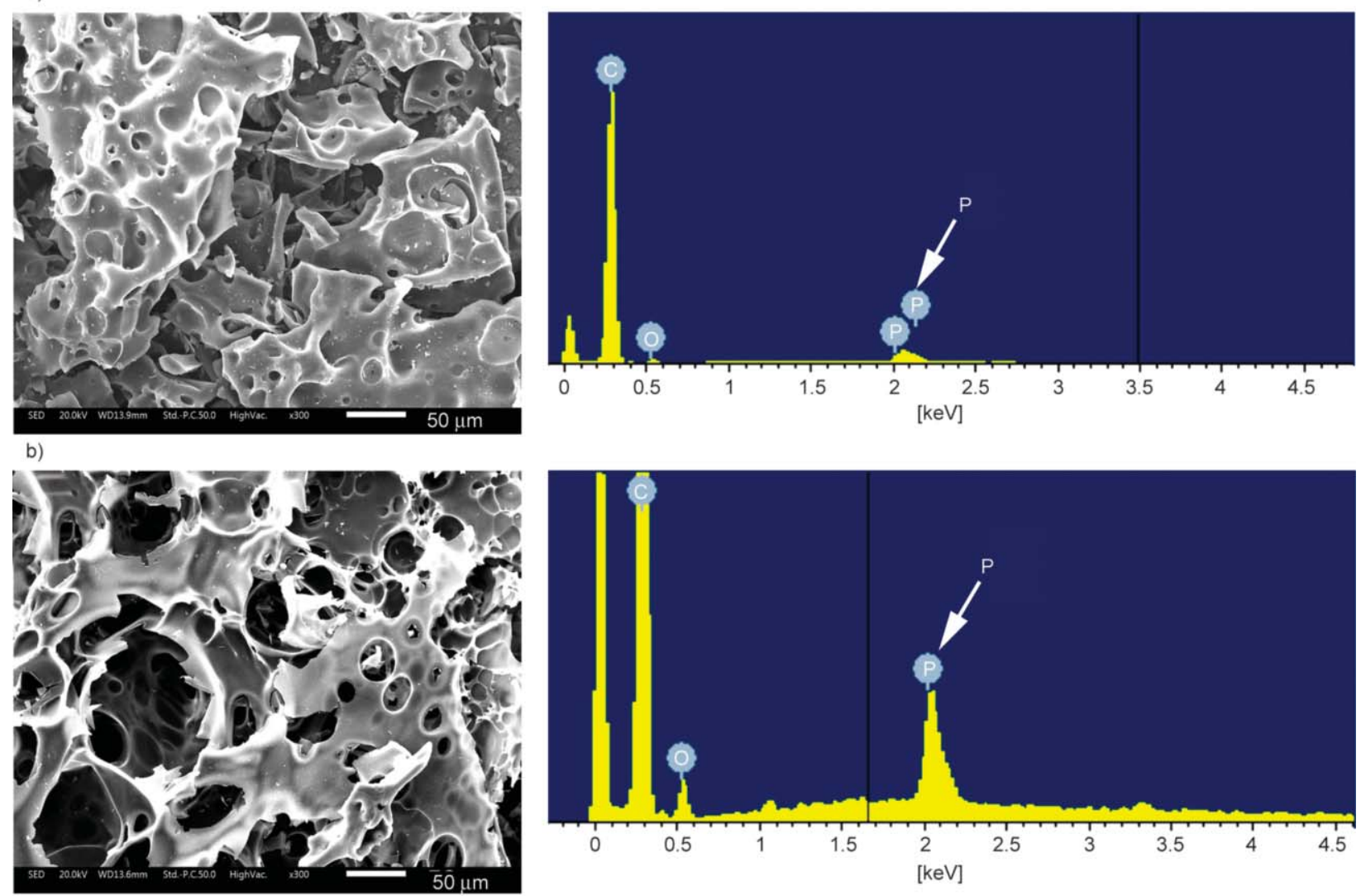

Figure 9. SEM images and EDX patterns of char layers in PI films after ignition. (a) PI-a; (b) PI-b; and (c) PI-c. 
which insulated the PI matrix from heat and air. Thus, incorporation of FP100 is quite beneficial for enhancing the flame retardancy of the semi-alicyclic CPI films.

\subsection{Continuous production of PI-b film}

In view of the good combined properties of PI-b film, the possibility of continuous production of the film on the demonstration line was investigated. The industrial production of CPI films has been reviewed in our previous work [9]. The diagram of the biaxial stretching production line used for the continuous production of PI-b films in the current work is shown in Figure 10. This diagram is reprinted from the literature for the thin film production via solvent cast technology [33-35]. The whole production usually consists of four basic units, as shown in the figure. First, PI-a resin and PPZ FR were dissolved into industrial grade DMAc (water content $<200 \mathrm{ppm}$ ) to afford PI-b solution. Various fillers, including mold release agent (triphenyl phosphite, etc.), slipping agent (nanograde silica, etc.) and so on, were added. The absolute viscosity of the PI-b mixture solution was controlled to be $\sim 100 \mathrm{~Pa} \cdot \mathrm{s}$. Secondly, the PI-b solution was purified by fine filtration to remove any impurities and then cast onto the surface of a stainless steel belt via extrusion die head with a tailored rate of flow. Thirdly, the cast PI-b wet film was first dried on the steel belt at $80 \sim 180^{\circ} \mathrm{C}$ via hot air stream to remove about $80 \mathrm{wt} \%$ of the DMAc solvent. The dry film containing about $20 \mathrm{wt} \%$ DMAc was then stripped off the steel belt and biaxially stretched (machine direction, $\mathrm{MD}$ and transverse direction, TD) in the high-temperature oven at elevated temperatures up to $280^{\circ} \mathrm{C}$. The waste DMAc gas was collected and recovered via the solvent recovery system shown in Figure 10b. At last, the PI-b films with the residual DMAc content lower than $1.0 \mathrm{wt} \%$ was wounded and collected.

Continuous PI-b film with a width of $1000 \mathrm{~mm}$, the length of $1000 \mathrm{~m}$, and the thickness of $25 \pm 0.5 \mu \mathrm{m}$ (Figure 11) was successfully obtained in the demonstration line, proving the possibility for industrial production via solvent cast technology. The properties of the PI-b film produced in the lab and in the demonstration line were compared, and the results are listed in Table 4. It can be clearly seen that similar or slightly enhanced thermal, optical, and flame retardancy properties and obviously improved tensile properties were observed for the mass production

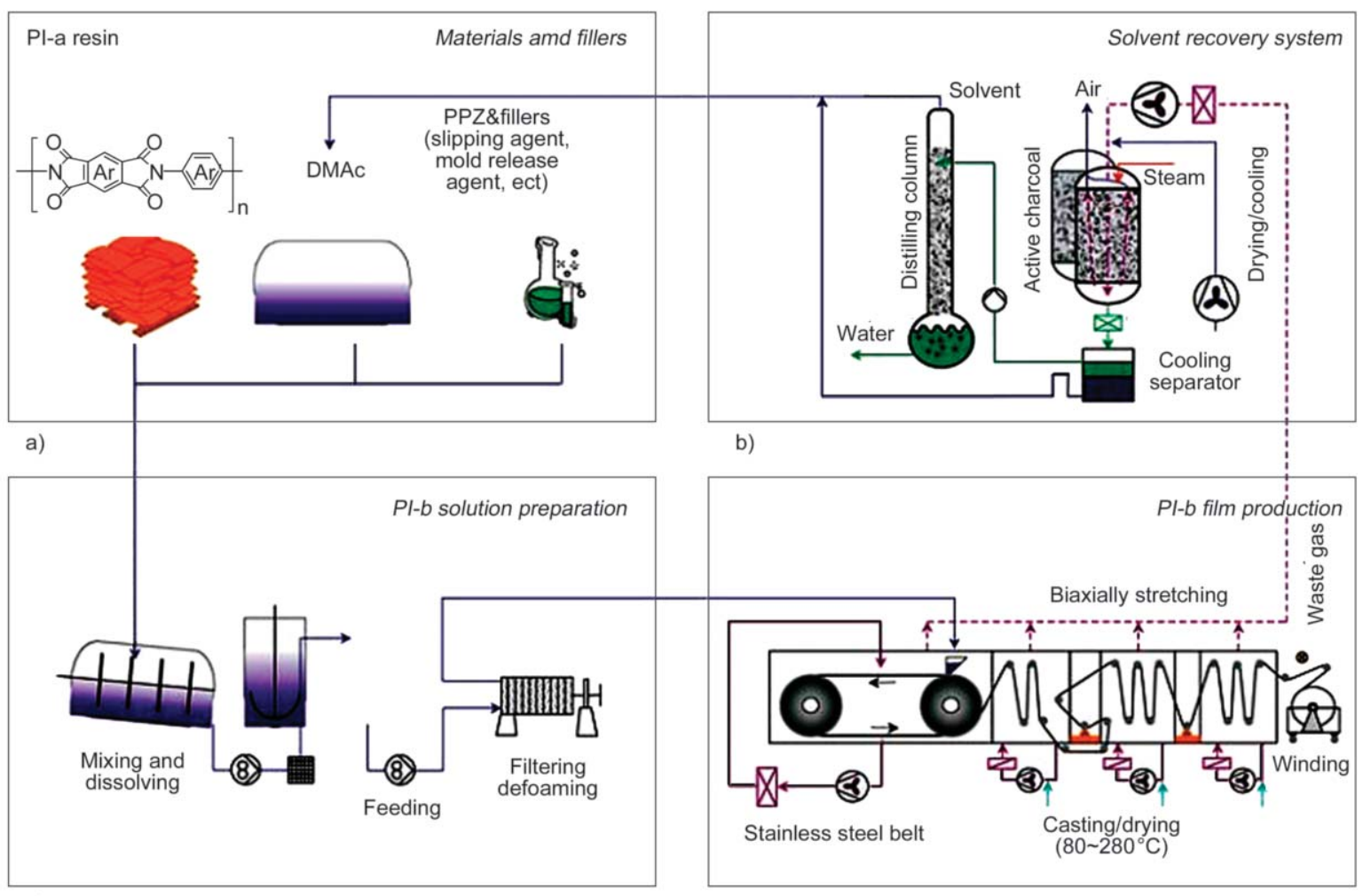

c)

d)

Figure 10. Diagrammatic production line for 1000 mm-width PI-b film. (a) materials and fillers; (b) solvent recovery system; (c) PI-b solution preparation; (d) PI-b film production. 
Table 4. Comparison of properties of CPI/PPZ film produced in lab (PI-b) and in demonstration line (PI-b').

\begin{tabular}{|c|c|c|c|c|c|c|c|c|c|c|c|}
\hline \multirow[b]{2}{*}{ PI } & \multirow{2}{*}{$\begin{array}{c}T_{\mathbf{g}}^{\mathbf{a}} \\
{\left[{ }^{\circ} \mathbf{C}\right]}\end{array}$} & \multirow{2}{*}{$\begin{array}{c}T_{400}{ }^{b} \\
{[\%]}\end{array}$} & \multirow{2}{*}{$\begin{array}{c}T_{\mathbf{S}^{\mathrm{c}}} \\
{[\mathrm{MPa}]}\end{array}$} & \multirow{2}{*}{$\begin{array}{c}E_{\mathbf{b}}{ }^{\mathrm{c}} \\
{[\%]}\end{array}$} & \multirow{2}{*}{$\begin{array}{c}\text { LOI }^{\mathrm{d}} \\
{[\%]}\end{array}$} & \multirow{2}{*}{$\begin{array}{c}\text { UL-94 } \\
\text { level }\end{array}$} & \multicolumn{5}{|c|}{ Cone calorimetry } \\
\hline & & & & & & & $\begin{array}{c}T_{H}{ }^{\mathrm{e}} \\
{\left[\mathrm{MJ} / \mathrm{m}^{2}\right]}\end{array}$ & $\begin{array}{c}p H R R^{\mathrm{f}} \\
{\left[\mathrm{kW} / \mathrm{m}^{2}\right]}\end{array}$ & $\begin{array}{l}T S P^{g} \\
{\left[\mathrm{~m}^{2}\right]}\end{array}$ & $\begin{array}{l}p S P R^{\mathrm{h}} \\
{\left[\mathrm{m}^{2} / \mathrm{s}\right]}\end{array}$ & $\begin{array}{c}p R S R^{\mathrm{i}} \\
{\left[\left(\mathbf{m}^{2} / \mathbf{s}\right) / \mathbf{m}^{2}\right]}\end{array}$ \\
\hline PI-b & 325.6 & 83.9 & 86.3 & 13.6 & 41.2 & VTM-0 & 0.23 & 2.79 & 0.033 & 0.0023 & 0.2640 \\
\hline PI-b' & 322.3 & 84.1 & 96.1 & 116.1 & 42.0 & VTM-0 & 0.39 & 3.59 & 0.027 & 0.0012 & 0.1428 \\
\hline
\end{tabular}

${ }^{\mathrm{a}}$ Glass transition temperature;

${ }^{\mathrm{b}}$ Transmittance at the wavelength of $400 \mathrm{~nm}$;

${ }^{\mathrm{c}} T_{\mathrm{S}}$ : Tensile strength by the average values of MD and TD directions;

$E_{\mathrm{b}}$ : elongation at break by the average values of MD and TD directions;

${ }^{\mathrm{d}}$ Limited oxygen index;

${ }^{\mathrm{e}}$ Total heat release;

Peak of heat release rate;

gTotal smoke production;

hPeak of smoke production rate;

${ }^{i}$ Peak of rate of smoke release.

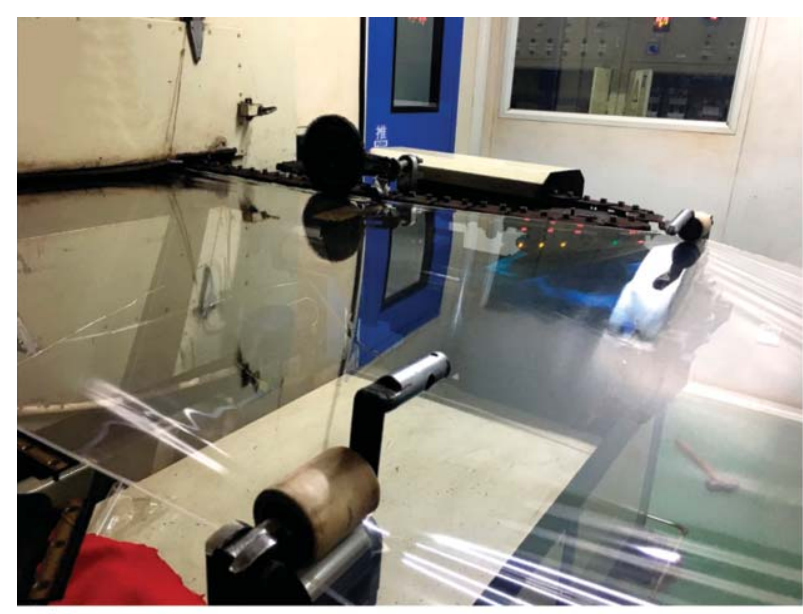

a)

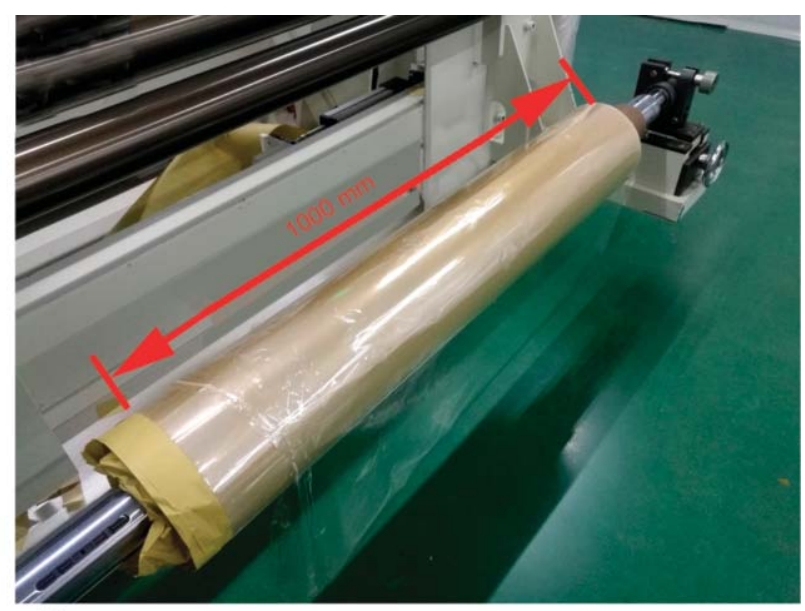

b)

Figure 11. Continuous production of $1000 \mathrm{~mm}$ width PI-b film. (a) biaxially stretching, (b) winding.

PI-b' film compared with the laboratory level PI-b one. For instance, PI-b' film showed tensile strength $\left(T_{\mathrm{s}}\right)$ and elongation at break $\left(E_{\mathrm{b}}\right)$ value of $96.1 \mathrm{MPa}$ and $116.1 \%$, respectively, which are obviously higher than those of the PI-b $\left(T_{\mathrm{s}}=86.3 \mathrm{MPa} ; E_{\mathrm{b}}=13.6 \%\right)$. This is undoubtedly attributed to the biaxially stretching processing during the film production, by which the molecular chains in the PI film were fully oriented, thus improving their tensile properties significantly [36]. On the other hand, FP100 also played as a role of plasticizer, which is beneficial for increasing the $E_{\mathrm{b}}$ values of the films.

\section{Conclusions}

Aiming at enhancing the flame retardancy of the semi-alicyclic PI-a(CHDA-ODA) film while maintaining its intrinsic high thermal and optical properties, PPZ (FP100) was incorporated into the PI matrix to afford PI composite films with different loading amounts of flame retardant. Experimental results indicated that the PI composite films possessed the best combined properties when the loading amount of PPZ was lower than $15 \mathrm{wt} \%$. The laboratory-level PI-b(CHDA-ODA-FP100-5) film showed a $T_{\mathrm{g}}$ value of $325.6{ }^{\circ} \mathrm{C}$, a $T_{400}$ value of $83.9 \%$, an LOI value of $41.2 \%$, a UL94 level of VTM-0, and low heat-releasing and smoke-releasing feature during combustion. Good comprehensive properties make it a good candidate as high-performance components for advanced optoelectronic applications. For this purpose, the possibility for the continuous production of the PI-b film on our previously built demonstration line was endeavored, and satisfying results were obtained. By optimizing the processing parameters for the modified solvent cast technology, continuous PI-b films with a length of $1000 \mathrm{~m}$, a width of $1000 \mathrm{~mm}$, and a thickness of $25 \pm 0.5 \mu \mathrm{m}$ were successfully obtained. Similar thermal, optical, and flame retardancy properties, and obviously improved tensile properties were observed for the mass production PI-b film compared with the laboratory level one. The current work might provide beneficial information and engineering 
data for the future mass production of the semi-alicyclic CPI films.

\section{Acknowledgements}

Financial supports from the Shandong Key Research and Development Program (No. 2019JZZY020235), Fundamental Research Funds of China University of Geosciences, Beijing (No.2-9-2019-127), and National Natural Science Foundation of Shanghai (No. 17ZR1411800) are gratefully acknowledged.

\section{References}

[1] Huang S., Liu Y., Zhao Y., Ren Z., Guo C-F.: Flexible electronics: Stretchable electrodes and their future. Advanced Functional Materials, 29, 1805924/1-1805924/15 (2019).

https://doi.org/10.1002/adfm.201805924

[2] Choi M-C., Kim Y., Ha C-S.: Polymers for flexible displays: From material selection to device applications. Progress in Polymer Science, 33, 581-630 (2008). https://doi.org/10.1016/j.progpolymsci.2007.11.004

[3] Benight S-J., Wang C., Tok J. B. H., Bao Z.: Stretchable and self-healing polymers and devices for electronic skin. Progress in Polymer Science, 38, 1961-1977 (2013).

https://doi.org/10.1016/j.progpolymsci.2013.08.001

[4] MacDonald W-A.: Engineered films for display technologies. Journal of Materials Chemistry, 14, 4-10 (2004). https://doi.org/10.1039/B310846P

[5] Chen J-L., Liu C-T.: Technology advances in flexible displays and substrates. IEEE Access, 1, 150-158 (2013). https://doi.org/10.1109/access.2013.2260792

[6] Mativenga M., Geng D., Kim B., Jang J.: Fully transparent and rollable electronics. ACS Applied Materials Interface, 7, 1578-1585 (2015). https://doi.org/10.1021/am506937s

[7] Kim J., Kim H., Baek M., Lee J., Park M., Kim C., Hwang Y., Park J.: P-137: Vt Behaviors of LTPS-TFT fabricated on PI substrate for flexible applications. SID Symposium Digest Technical Papers, 48, 1773-1776 (2017). https://doi.org/10.1002/sdtp.12021

[8] Bu L., Carbajal L., Chang M., Chen J., Johnson J. C., Kourtakis K., Lamontia M., Li A., Liao K., Liu S., Mulzer M., Nambiar R., Radu N., Wang D., Zhang J., LeCloux D.: Advanced materials for flexible displays. SID Symposium Digest Technical Papers, 50, 727-730 (2019). https://doi.org/10.1002/sdtp.13023

[9] Ni H-J., Liu J-G., Wang Z-H., Yang S-Y.: A review on colorless and optically transparent polyimide films: Chemistry, process and engineering applications. Journal of Industrial Engineering Chemistry, 28, 16-27 (2015).

https://doi.org/10.1016/j.jiec.2015.03.013
[10] Wu X., Liu J., Jiang G., Zhang Y., Guo C., Zhang Y., Qi L., Zhang X.: Highly transparent preimidized semialicyclic polyimide varnishes with low curing temperatures and desirable processing viscosities at high solid contents: Preparation and applications for LED chip passivation. Journal of Materials Science: Materials in Electronics, 30, 549-560 (2019). https://doi.org/10.1007/s10854-018-0321-5

[11] Jiang G-I., Wang D-Y., Du H-P., Wu X., Zhang Y., Tan Y-Y., Wu L., Liu J-G., Zhang X-M.: Reduced coefficients of linear thermal expansion of colorless and transparent semi-alicyclic polyimide films via incorporation of rigid-rod amide moiety: Preparation and properties. Polymers, 12, 413/1-413/15 (2020). https://doi.org/10.3390/polym12020413

[12] Zhang Q., Tsai C-Y., Li L-J., Liaw D-J.: Colorless-tocolorful switching electrochromic polyimides with very high contrast ratio. Nature Communication, 10, 1239/11239/8 (2019). https://doi.org/10.1038/s41467-019-09054-8

[13] Zhuang Y., Seong J. G., Lee Y. M.: Polyimides containing aliphatic/alicyclic segments in the main chains. Progress in Polymer Science, 92, 35-88 (2019). https://doi.org/10.1016/j.progpolymsci.2019.01.004

[14] Hasegawa M., Horie K.: Photophysics, photochemistry, and optical properties of polyimides. Progress in Polymer Science, 26, 259-335 (2001). https://doi.org/10.1016/S0079-6700(00)00042-3

[15] Yi C., Li W., Shi S., He K., Ma P., Chen M., Yang C.: High-temperature-resistant and colorless polyimide: Preparations, properties, and applications. Solar Energy, 195, 340-354 (2020). https://doi.org/10.1016/j.solener.2019.11.048

[16] Min H., Kang B., Shin Y-S., Kim B., Lee S-W., Cho J-H.: Transparent and colorless polyimides containing multiple trifluoromethyl groups as gate insulators for flexible organic transistors with superior electrical stability. ACS Applied Materials Interfaces, 12, 18739-18747 (2020). https://doi.org/10.1021/acsami.9b23318

[17] Simone C-D., Vaccaro E., Scola D-A.: The synthesis and characterization of highly fluorinated aromatic polyimides. Journal of Fluorine Chemistry, 224, 100112 (2019). https://doi.org/10.1016/j.jfluchem.2019.05.001

[18] Zhang Y., Qu L., Liu J., Wu X., Zhang Y., Zhang R., Qi H., Zhang X.: Synthesis and characterization of hightemperature-resistant and optically transparent polyimide coatings for potential applications in quartz optical fibers protection. Journal of Coating Technology and Research, 16, 511-520 (2019). https://doi.org/10.1007/s11998-018-0129-5

[19] Lan Z., Li C., Yu Y., Wei J.: Colorless semi-alicyclic copolyimides with high thermal stability and solubility. Polymers, 11, 1319/1-1319/11 (2019). https://doi.org/10.3390/polym11081319 
[20] Matsumoto T., Mikami D., Hashimoto T., Kaise M., Takahashi R., Kawabata S.: Alicyclic polyimides - A colorless and thermally stable polymer for opto-electronic devices. Journal of Physics: Conference Series, 187, 012005/1-012005/11 (2009).

https://doi.org/10.1088/1742-6596/187/1/012005

[21] Matsumoto T., Ozawa H., Ishiguro E., Komatsu S.: Properties of alicyclic polyimides with bis-spironorbornane structure prepared in various solvents. Journal of Photopolymer Science and Technology, 29, 237-242 (2016).

https://doi.org/10.2494/photopolymer.29.237

[22] Hu X., Yan J., Wang Y., Mu H., Wang Z., Cheng H., Zhao F., Wang Z.: Colorless polyimides derived from 2R,5R,7S, 10S-naphthanetetracarboxylic dianhydride. Polymer Chemistry, 8, 6165-6172 (2017). https://doi.org/10.1039/C7PY01048F

[23] Kanosue K., Hirata S., Vacha M., Augulis R., Gulbinas V., Ishige R., Ando S.: A colorless semi-aromatic polyimide derived from a sterically hindered bromine-substituted dianhydride exhibiting dual fluorescence and phosphorescence emission. Materials Chemistry Frontiers, 3, 39-49 (2019). https://doi.org/10.1039/C8QM00409A

[24] Mi Z., Wang S., Hou Z., Liu Z., Jin S., Wang X., Wang D., Zhao X., Zhang Y., Zhou H., Chen C.: Soluble polyimides bearing (cis, trans)-hydrogenated bisphenol A and (trans, trans)-hydrogenated bisphenol A moieties: Synthesis, properties and the conformational effect. Polymers, 11, 854/1-854/19 (2019).

https://doi.org/10.3390/polym11050854

[25] Zhuang Y., Orita R., Fujiwara E., Zhang Y., Ando S.: Colorless partially alicyclic polyimides based on Tröger's base exhibiting good solubility and dual fluorescence/ phosphorescence emission. Macromolecules, 52, 38133824 (2019).

https://doi.org/10.1021/acs.macromol.9b00273

[26] Wu X., Jiang G., Zhang Y., Wu L., Jia Y., Tan Y., Liu J., Zhang X.: Enhancement of flame retardancy of colorless and transparent semi-alicyclic polyimide film from hydrogenated-BPDA and 4,4'-oxydianiline via the incorporation of phosphazene oligomer. Polymers, 12, 90/190/16 (2020).

https://doi.org/10.3390/polym12010090

[27] Grabiec E., Schab-Balcerzak E., Wolińska-Grabczyk A., Jankowski A., Jarząbek B., Kożuch-Krawczyk J., Kurcok M.: Physical, optical and gas transport properties of new processable polyimides and poly(amideimide)s obtained from 4,4'-[oxybis(4,1-phenylenethio)]dianiline and aromatic dianhydrides. Polymer Journal, 43, 621629 (2011).

https://doi.org/10.1038/pj.2011.28
[28] Hasegawa M., Hirano D., Fujii M., Haga M., Takezawa E., Yamaguchi S., Ishikawa A., Kagayama T.: Solutionprocessable colorless polyimides derived from hydrogenated pyromellitic dianhydride with controlled steric structure. Journal of Polymer Science Part A: Polymer Chemistry, 51, 575-592 (2012).

https://doi.org/10.1002/pola.26407

[29] Mu X., Yuan B., Hu W., Qiu S., Song L., Hu Y.: Flame retardant and anti-dripping properties of polylactic acid/poly(bis(phenoxy)phosphazene)/expandable graphite composite and its flame retardant mechanism. RSC Advances, 5, 76068-76078 (2015).

https://doi.org/10.1039/c5ra12701g

[30] Fang Y., Miao J., Yang X., Zhu Y., Wang G.: Fabrication of polyphosphazene covalent triazine polymer with excellent flame retardancy and smoke suppression for epoxy resin. Chemistry Engineering Journal, 385, 123830/1-123830/13 (2020).

https://doi.org/10.1016/j.cej.2019.123830

[31] Velencoso M. M., Battig A., Markwart J-C., Schartel B., Wurm F. R.: Molecular firefighting - How modern phosphorus chemistry can help solve the challenge of flame retardancy. Angewandte Chemie International Edition, 57, 10450-10467 (2018).

https://doi.org/10.1002/anie.201711735

[32] He W., Song P., Yu B., Fang Z., Wang H.: Flame retardant polymeric nanocomposites through the combination of nanomaterials and conventional flame retardants. Progress in Materials Science, 114, 100687/1-100687/49 (2020).

https://doi.org/10.1016/j.pmatsci.2020.100687

[33] Siemann U.: Solvent cast technology - A versatile tool for thin film production. Progress in Colloid and Polymer Science, 130, 1-14 (2005). https://doi.org/10.1007/b107336

[34] Machell J-S., Greener J., Contestable B-A.: Optical properties of solvent-cast polymer films. Macromolecules, 23, 186-194 (1990). https://doi.org/10.1021/ma00203a033

[35] Unsal E., Cakmak M.: Real-time characterization of physical changes in polyimide film formation: From casting to imidization. Macromolecules, 46, 8616-8627 (2013). https://doi.org/10.1021/ma401361w

[36] Fay C. C., Stoakley D. M., St Clair A. K.: Molecularly oriented films for space applications. High Performance Polymers, 11, 145-156 (1999).

https://doi.org/10.1088/0954-0083/11/1/012 